\title{
Source of Information in Times of Health Crisis: Evidence from Turkey During COVID-19
}

\author{
Ekmel Geçer $^{1}$, Murat Yıldırım²,3* ${ }^{2}$ Ömer Akgül ${ }^{1}$ \\ ${ }^{1}$ Department of Psychology, University of Health Sciences, İstanbul, Turkey \\ ${ }^{2}$ Department of Psychology, Ağrı İbrahim Çeçen University, Ağrı, Turkey \\ ${ }^{3}$ Department of Neuroscience, Psychology and Behaviour, University of Leicester, \\ Leicester, UK
}

Cite as: Geçer, E., Yıldırım, M., \& Akgül, Ö. (2020). Source of Information in Times of Health Crisis: Evidence from Turkey During COVID-19. PsyArXiv, 1-22. doi: 10.31234/osf.io/x76mn

Authors note

*Correspondence: Dr Murat Yıldırım, Ağrı İbrahim Çeçen University, Department of Psychology, Faculty of Science and Letters, Erzurum Yolu 4 Km 04100, Merkez, Ağrı, Turkey; tel: +904722159863, email: muratyildirim@agri.edu.tr 


\begin{abstract}
Aim: Media as a source of information can shape public opinion toward COVID-19 response. Identifying how and where people seek information during COVID-19 outbreak is vital to convey the most effective message about managing the COVID-19 crisis. The purpose of this study was to determine the source of information and investigate the role of various demographic factors - age, gender, educational attainment, and perceived economic level on source of information.
\end{abstract}

Subject and Methods: An online survey $(n=4,624)$ was conducted on the Turkish public during early stages of the COVID-19.

Results: The results showed that internet journalism and social media were the most preferable source of information. Higher age, educational attainment, and economic level were related to higher levels of seeking information from TV, newspaper, internet journalism, and informative meetings. Females obtained information more from their friends and family, and social media than males. High school graduates or below watched more TV and obtained less information from internet journalism, while university graduates sought information from their families and friends, and that postgraduates attended informative meeting and read newspapers. People with medium and high economic status respectively watched more TV and read more newspapers while people with low socioeconomic status attended less in informative meetings.

Conclusion: In sum, this study provides evidence that a source of information might be influenced by demographic factors. Researchers and policymakers can use a source of information to develop crisis-response strategies by considering variations in the demographic factors.

Keywords: COVID-19, Coronavirus, Source of information, Demographic factors, Turkey 


\section{Source of Information in Times of Health Crisis: The Turkish Case During COVID-19}

The world seems to be under the threat of the fastest spreading novel Coronavirus (COVID-19). In December 2019, World Health Organisation (WHO, 2020) reported many pneumonia cases from Wuhan city in China. On 12 December 2019, the first case of the COVID-19 epidemic was reported with unexplained pneumonia and 27 viral pneumonia cases with seven being severe, were officially announced on December 31, 2019 (Sahin et al., 2020). After spreading country-wide on 13 January 2020, the disease crossed Chinese borders and seen in Thailand. From that time, the COVID-19 exponentially spread to more than 185 countries, with the USA, Italy, and Spain being the worst affected countries. The COVID-19 outbreak has forced governments to put strict measures in place to control the virus.

As of 22 May 2020, there were a total of 5,118,416 confirmed cases, 333,212 deaths, and 1,960,223 recovered cases of COVID-19 around the world (Center for Systems Science and Engineering, 2020). Due to the rapidity of spreading the virus, on 11 March 2020 it has been recognised as the first pandemic derived from the coronavirus family by World Health Organisation (WHO, 2020). While many empirical studies have been carrying out to provide antiviral vaccine (Mehta, McAuley, Brown, Sanchez, \& Tattersal, 2020), others have been conducting to mostly understand the risk factors associated with rates high rates of mortality (Zhou et al., 2020). Maintaining mental health plays an important role during the outbreak as some previous studies showed that social disconnectedness and isolation are negatively related to physical and mental health (Cornwell, \& Waite, 2009). Identifying sources of information and characteristics of people who seek information from different outlets are important for policy makers to develop crisis-response strategies. As such, this study endeavoured to identify source of information and explore the role of various demographic 
factors such as gender, education level, and perceived socio-economic status on source of information during COVID-19 pandemic.

\section{Seeking Information in Times of Crisis}

Sources of information during infectious diseases outbreak plays a key role to successfully manage public health risk communication. During outbreaks, public needs to access reliable information that fulfils their needs to engage in protective health behaviours (Vaughan, \& Tinker, 2009). COVID-19 pandemic can cause uncertainties and requires people to change their behaviours and attitudes toward the pandemic such as changing their

daily news consumption and the ways they are receiving it. The credibility and usefulness of sources of information related to pandemic can be useful to direct risk communication channels and messages (Jehn, Kim, Bradley, \& Lant, 2011).

With new technological innovation, particularly with regards to cannels of electronic information sources, people tend to largely engage in social networking sites such as internet journalism and social media where they access to information (Jardine, Boerner, Boyd, \& Driedger, 2015). Report showed that people from different socioeconomic background tend to access information from different media channels. For example, Internet use has been found to be significantly differ by age group, level of education and income (Statistics Canada, 2010). Studies also suggest that there is a strong association with the level of education and news consumption. In other words, those who are well and formally educated seem to be more following the daily news (Poindexter \& McCombs, 2001). This connection is also visible in the relationship between news and socioeconomic status although not much known how much this impact altered over the years. For instance, people from lower socioeconomic status do not that frequently check daily issues although they do have more prediction about what is happening around them (Bergström, Strömbäck, \& Arkhede, S 2019; 
Norris \& Inglehart, 2013). With regard to age, elderly people tend to seek information from close circle or television (Elareshi, 2013, p. 49).

Due to the nature of the COVID-19 pandemic which requires people to stay at home and practice social distancing, people may prefer to use social networking sites as sources of information as they are instant and interactive platforms. This argument has been documented in previous research that during the $\mathrm{H} 1 \mathrm{~N} 1$ outbreak and subsequent vaccination program, people predominantly used social networking sites as a source of information (Lam, \& McGeer, 2012).

Identifying how and where people seek information during COVID-19 outbreak plays an important role for the government to convey the most effective strategies related to controlling the COVID-19 crisis and inform the public about the progress made. As such, the aims of this study were three-fold: (i) to determine the sources of information where public seek information about COVID-19, (ii) to explore the relationship between demographic factors (e.g., age, gender, education level, socioeconomic status), and sources of information and (iii) to examine the impact of demographic variables on sources of information.

\section{Method}

\section{Participants}

The population of this study includes 4,624 Turkish speaking individuals between 18 and 89 years of age $(M=30.29$ years old, $S D=10.97)$. In total, $3236(470 \%)$ of the participants were female and 1388 (30\%) were male. In terms of educational level, 500 (10.81\%) were high school graduates or below, 2932 participants $(63.41 \%)$ were university graduates and $1192(25.78 \%)$ were holding a postgraduate degree. A total of $578(12.50 \%)$ perceived their socioeconomic status as low while $3557(76.92 \%)$ perceived as medium and 
$489(10.58 \%)$ high. Concerning marital status, 2698 (58.35\%) participants were single, 1787 (38.65\%) were married, and 139 (3\%) were widowed/separated.

\section{Measures}

\section{Demographics}

A sociodemographic data form was created to collect demographics. Participants were asked to provide information about their age, gender, education level, marital status, and selfreported perceived economic level.

\section{Source of information form}

We asked participants how often they used the following channels as an information source: TV, friends and family, informative meetings, newspaper, internet journalism, and social media. Each source was rated on a 3-point rating scale ranging from 1 (never) to 3 (often). Higher scores represent higher levels of engagement with the relevant source of information.

\section{Procedure}

This study was part of a larger research project examining the impact of COVID-19 pandemic on psychological health. Before completing the study measures, information about the study was presented on the first page of the online survey. Online informed consent was obtained from all participants before entering their demographic information. Those who agreed to collaborate were allowed to proceed to complete the measures which were presented in the same order by the survey software. The average time needed to complete the study was about 5 minutes. All participants were voluntarily contributed to the study and they did not receive any compensation. The study procedure was carried out according to the ethical standards established in the 1964 Declaration of Helsinki and its later amendments. All data collection occurred between 17 March and 1 April 2020. 


\section{Data analysis}

SPSS 24.0 for Windows was used for statistical analysis of the data. Descriptive statistics were reported to understand the levels of source of information among participants. Correlation analysis was performed to test the relationships between demographic variables and sources of information. An independent sample t-test was used to compare gender across the sources of information. One-way Analysis of Variance (ANOVA) was conducted to compare the source of information by education and economic levels. Skewness and kurtosis statistics were employed to test the assumption of normality where skewness $<2$ and kurtosis $<7$ representing an acceptable symmetry for a normal univariate distribution (Curran, West, \& Finch, 1996).

\section{Results}

\section{Levels of source of information}

Mean and standard deviation about the levels of source of information are reported in Table 1 . The most commonly used source of information was internet journalism followed by social media. The least commonly used source of information was newspaper followed by informative meetings.

\section{Insert Table 1 about here}

\section{Correlation between demographic variables and source of information}

Correlation results are presented in Table 2. Higher age was correlated with higher levels of watching TV, attending informative meetings and reading newspapers and lower levels of getting information from friends and family, and social media. Females were more likely to get information from their friends and family and social media, and less from a newspaper. People with higher levels of education were more likely to receive information from informative meetings, newspapers, and internet journalism and less likely to receive 
information from TV. Those who had high levels of perceived economic level tended to report higher levels of receiving information from informative meetings, newspapers, and internet journalism.

\section{Insert Table 2 about here}

\section{Gender differences in source of information}

An independent sample $t$-test was performed to compare the source of information by gender. The results showed that females obtained information more from their friends and family (2.46 vs 2.16 ) and social media (2.77 vs 2.63$)$ than males, while males reported higher levels of reading newspapers (1.33 vs 1.42$)$ than females. The results are presented in Table 3.

\section{Insert Table 3 about here}

\section{Effects of education level on source of information}

One-way ANOVA was used to examine the differences in source of information by the education levels (see Table 4). There were statistically significant differences between groups means in respect to TV, $F(2,4623)=6.92, p<0.01)$. and family and friends, $F(2$, $4623)=5.22, p<0.01)$. Tukey post hoc test revealed that high school graduates or below $(2.29 \pm 0.72)$ and university graduates $(2.22 \pm 0.70)$ watch more TV than postgraduates $(2.15$ $\pm 0.74)$. It also showed that university graduates $(2.39 \pm 0.62)$ obtained more information from their families and friends in comparison to high school graduates or below $(2.31 \pm 0.65)$ and postgraduates $(2.34 \pm 0.63)$. Because the Levene's $F$ test demonstrated that the homogeneity of variance assumption was not meet for informative meetings, newspaper, internet journalism, and social media (all $p$ values $<0.01$ ), we address this issue by performing the Welch's $F$ test. The results showed a statistically significant effects for all remaining source of information by education level: informative meetings, Welch's $F$ (2, 
$1248.49)=6.82, p<.001$; newspaper, Welch's $F(2,1270.56)=19.95, p<.001$; internet journalism, Welch's $F(2,1196.43)=9.74, p<.001 ;$ Welch's $F(2,1203.18)=13.64, p<$ .001 . The results of Games-Howell post hoc analysis showed that postgraduates $(1.51 \pm 0.68)$ participated more in an informative meeting than high school graduates or below $(1.40 \pm$ $0.67)$ and university graduates $(1.43 \pm 0.64)$. Postgraduates $(1.46 \pm 0.64)$ read more newspapers than high school graduates or below $(1.31 \pm 0.55)$ and university graduates $(1.33$ $\pm 0.57)$. High school graduates or below $(2.62 \pm 0.63)$ obtain less information from internet journalism when compared with university graduates $(2.75 \pm 0.50)$ and postgraduates $(2.75 \pm$ $0.51)$. They $(2.62 \pm 0.62)$ also engage in social media less than university graduates $(2.76 \pm$ $0.52)$ and postgraduates $(2.70 \pm 0.556)$. University graduate was more active in engaging in social media than postgraduates.

\section{Insert Table 4 about here}

\section{Effects of perceived economic level on source of information}

One-way ANOVA was performed to examine the differences in source of information by perceived economic levels (see Table 5). There were statistically significant differences between group means with regards to TV, $F(2,4623)=5.0, p<0.01)$. Tukey post hoc test indicated that those who had a medium economic level $(2.22 \pm 0.71)$ considered TV as a useful information source than those who had a low economic level $(2.13 \pm 0.74)$. There were no statistically significant differences between groups means concerning getting information from friends and families, $F(2,4623)=1.21, p>0.05)$, and social media, $F(2,4623)=0.62$, $p>0.05)$. However, the Levene's $F$ test showed that the homogeneity of variance assumption was violated for informative meetings, newspaper, and internet journalism (all $p$ values $<$ 0.05). To correct this, the Welch's $F$ test was therefore utilized. The analysis demonstrated a statistically significant effects for informative meetings, Welch's $F(2,888.73)=5.07, p<$ 
.001 and newspaper, Welch's $F(2,888.29)=8.85, p<.001$, but not for internet journalism, Welch's $F(2,884.71)=2.29, p>.005$. An analysis of post hoc test as determined by GamesHowell revealed that people with low economic level $(1.37 \pm 0.66)$ attended less in informative meetings compared to people with medium $(1.45 \pm 0.65)$ and high $(1.50 \pm 0.67)$ socioeconomic status. Similarly, people with a high economic level $(1.45 \pm 0.65)$ read more newspapers than those with medium $(1.36 \pm 0.59)$ and low $(1.30 \pm 0.55)$ economic levels. The mean differences between medium and low socioeconomic status were also statistically significant.

\section{Insert Table 5 about here}

\section{Discussion}

To the best of our knowledge, this is the first study identifying the source of information and examining the impact of demographic factors on source of information during the early phase of COVID-19 outbreak in a large sample drawn from the general public in Turkey. The results showed that the most preferable source of information was rated as internet journalism and social media. This result is expected since internet and social networking sites are widely used across the world. With easy access to technological devices such as phone and iPad, receiving information from internet journalism and social media can be more convenient and cost effective to access information for people during pandemic. Source of information during public health crisis can play a key role in protecting mental health if used efficiently. Mental Health Commission of Canada (2020) underscored that it is critical to maintain positive mental health by carefully choosing credible sources of information during COVID-19 outbreak.

The results also showed that higher age, educational attainment, and economic status were related to higher levels of seeking information from TV, newspaper, internet journalism, 
and informative meetings. These results are partly consistent with previous findings. Younger people were found to be more comfortable using internet as a source of information. People with lower education attainment may lack in knowledge of or receive information from virtual platforms such as internet journalism (Ramsey et al., 2009). The differences in the results of this study and those of previous studies are indeed expected due to the nature of COVID-19 which requires all people from different socioeconomic backgrounds to stay at home. Thus, it is possible that they use various sources of information (e.g., TV and internet journalism) for cross-validation of the credibility of the information during pandemic.

With regards to gender differences, females reported that they mainly received information more from their friends and family, and social media than males. This can be related with cultural background where Turkish women typically gather at homes and discuss everyday matters (Tuncer, 2018). Although COVID-19 pandemic imposes people to stay at home, it is plausible to assume that Turkish women can still receive information from their families and friends over the phone or other communication tools. However, the accuracy of information from such sources can be an issue of a dispute as studies suggest that people with better access to information through mass communication tools receive more favourable content (Strömberg, 2004).

Concerning the education level, we found that participants significantly differ in seeking information from different sources. While those with low education attainment (e.g., high school graduate or below) reported that they sought information mainly from traditional media such as TV, highly educated people received information from relatively contemporary sources of information (e.g., internet journalism, informative meeting). These results demonstrate that those who have higher education level are more familiar with digital media technologies and prefer receiving information from online sources. Although misinformation is highly likely on online platforms, and new(s) media literacy should carefully be considered 
at this level too, because online news webs deliver an unceasing stream of information, provide instantly updated content, clear infographics, leisure, and cultural products based on the understanding of readers' needs, people are more tended to apply them for the last updates.

In respect to socioeconomic status, seeking information from TV and newspapers were the most common sources of information among people with perceived medium and high socioeconomic status whereas the least reported source of information was attending informative meetings among people with perceived low socioeconomic status. Previous research suggests that social inequalities shape the forms of news consumption the decisions individuals take regarding news reading are related to their social status (Lindell, 2017). Although digital journalism leads the news sources in terms of socioeconomic status, people with higher positions also watch television and read newspapers while with lower ones participate informative meetings which at the same time shows that social inequalities in news consumption may increase. Therefore, social inequality in news consumption and sources may not only be about the number of news sources audience used but it is also a matter of how people receive their news and what mediums they rely on.

This study provides evidence that the source of information is significantly influenced by demographic factors. Academics, health officials and policy makers can consider the results of this study to develop effective crisis-response and health communication strategies in the light of variations in the demographic factors. Given that the differences in the ways for receiving the news and consuming it may be shaped by sociodemographic factors, awareness about how people acquire information can also help policy makers to inform public and deliver reliable information about pandemic in a faster and more convenient way.

This study has two main strengths. First, the data collection was held between 17 March - 1 April 2020 following the announcement of Turkey's outbreak on 17 March 2020. 
This early start allows us to timely assess where Turkish community receive information and how this differs based on demographic factors. Secondly, a large number of participants from different socioeconomic backgrounds could help to generalise the present findings to a wider population.

It is important to acknowledge that the current research has several drawbacks that need to be addressed in future studies. The first limitation was the use of online survey which may carry biases. Those who were unable to use the internet or have limited access were not satisfactorily represented in this investigation. Nonetheless, collecting data via an online survey appeared to be the most realistic and feasible method during COVID-19 pandemic. Secondly, there were only a limited number of variables examined in this study. Future research should consider how people are influenced by the news content and how this varies in different sources of information. Future studies should also specifically look at how the use of digital and portable news media vary according to demographics, socioeconomic and educational factors which will again allow policymakers to develop effective health communication strategies especially in times of crisis.

In sum, internet journalism and social media were the most preferable source of information. Age, educational attainment, and economic level were related to sources of information. There are significant variations in the gender, education level and economic status in seeking information from different sources. These results would facilitate development of effective crisis-response strategies during pandemic. 


\section{Acknowledgements}

The authors would like to thank all participants involved in this study for their corporation and support.

\section{Conflict of Interests}

The authors report no conflicts of interest.

\section{Funding/Support}

None. 


\section{References}

Bergström, A., Strömbäck, J., \& Arkhede, S. (2019). Towards rising inequalities in newspaper and television news consumption? A longitudinal analysis, 2000-2016. European Journal of Communication, 34(2), 175-189.

Center for Systems Science and Engineering (2020). Coronavirus COVID-19 global cases at Johns Hopkins University. Available at https://coronavirus.jhu.edu/map.html

Cornwell, E. Y., \& Waite, L. J. (2009). Social disconnectedness, perceived isolation, and health among older adults. Journal of Health and Social Behaviour, 50(1), 31-48.

Elareshi, M. (2013). News Consumption in Libya. Newcastle: Cambridge Scholars Publishing.

Jardine, C. G., Boerner, F. U., Boyd, A. D., \& Driedger, S. M. (2015). The more the better? A comparison of the information sources used by the public during two infectious disease outbreaks. PloS One, 10(10).

Jehn, M., Kim, Y., Bradley, B., \& Lant, T. (2011). Community knowledge, risk perception, and preparedness for the 2009 influenza A/H1N1 pandemic. Journal of Public Health Management and Practice, 17(5), 431-438.

Lam, P. P., \& McGeer, A. (2012). Communications Strategies for the 2009 Influenza A (H1N1) Pandemic. National Collaborating Centre for Infectious Diseases. Available at www.nccid.ca/files/Evidence_Reviews/H1N1_5_final.pdf

Lindell, J. (2017). Distinction recapped: Digital News Repertoires in The Class Structure. New Media \& Society, 1461444817739622.

Mehta, P., McAuley, D., Brown, M., Sanchez, E., \& Tattersal, R. (2020). COVID-19: consider cytokine storm syndromes and immunosuppression. The Lancet, 395(10229), 1033-1035. doi:10.1016/S0140-6736(20)30628-0 
Mental Health Commission of Canada. (2020). Choosing sources of information carefully is critical to COVID-19 mental well-being says Mental Health Commission of Canada. Available at https://www.mentalhealthcommission.ca/English/news$\underline{\text { article/13920/choosing-sources-information-carefully-critical-covid-19-mental-well- }}$ $\underline{\text { being-says }}$

Norris, P., \& Inglehart, R. (2013). Digital Divide. In R. Towse, \& H. Christian, Handbook on the Digital Creative Economy (pp. 90-104). Northampton: Edward Elgar.

Poindexter, P. M., \& McCombs, M. E. (2001). Revisiting the civic duty to keep informed in the new media environment. Journalism and Mass Communication Quarterly, 78, $113-126$.

Ramsey, S. D., Zeliadt, S. B., Arora, N. K., Potosky, A. L., Blough, D. K., Hamilton, A. S., ... \& Penson, D. F. (2009). Access to information sources and treatment considerations among men with local stage prostate cancer. Urology, 74(3), 509-515.

Rutakirwa, T. (2020). Understanding Coronavirus (COVID-19). London: Tonniez Publishing.

Sahin, A. R., Erdogan, A., Agaoglu, P. M., Dineri, Y., Çakırcı, A. Y., \& Senel, M. E. (2020). 2019 Novel Coronavirus (COVID-19) Outbreak: A Review of the Current Literature. EJMO, 4(1), 1-7. doi:10.14744/ejmo.2020.12220

Situation Report - 1. https://www.who.int/docs/default-source/coronaviruse/situationreports/20200121-sitrep-1-2019-ncov.pdf

Statistics Canada (2010). Internet use by individuals, by selected characteristics. Available at http://www. statcan.gc.ca/tables-tableaux/sum-som/101/cst01/comm35a-eng.htm

Strömberg, D. (2004). Radio's impact on public spending. Quarterly Journal of Economics, $119,189-221$. 
Tuncer, S. (2018). Women and Public Space in Turkey: Gender, Modernity and the Urban Experience. London: I. B. Tauris.

Vaughan, E., \& Tinker, T. (2009). Influenza Preparedness and Response for Vulnerable Populations. American Journal of Public Health, 99(S2), 331-332.

World Health Organization. (2020, January 21). Novel Coronavirus (2019-nCoV)

World Health Organization. (2020, March 11). WHO Director-General's opening remarks at the media briefing on COVID-19 - 11 March 2020. Available at https://www.who.int/dg/speeches/detail/who-director-general-s-opening-remarks-atthe-media-briefing-on-covid-19---11-march-2020

Zhou, F., Yu, T., Du, R., Fan, G., Liu, Y., Liu, Z., ... \& Guan, L. (2020). Clinical course and risk factors for mortality of adult inpatients with COVID-19 in Wuhan, China: a retrospective cohort study. The Lancet, 395(10229), 1054-1062. doi: 10.1016/S01406736(20)30566-3 
Table 1. Descriptive statistics about source of information

\begin{tabular}{lcccccccccc}
\hline & & & & & \multicolumn{2}{c}{ Skewness } & & \multicolumn{2}{c}{ Kurtosis } \\
Information source & Min & Max & Mean & SD & Statistic & SE & & Statistic & SE \\
\hline TV & 1 & 3 & 2.21 & 0.71 & -0.32 & 0.04 & & -1.01 & 0.07 \\
Friends and family & 1 & 3 & 2.37 & 0.63 & -0.47 & 0.04 & & -0.66 & 0.07 \\
Informative meetings & 1 & 3 & 1.45 & 0.66 & 1.18 & 0.04 & & 0.16 & 0.07 \\
Newspaper & 1 & 3 & 1.36 & 0.59 & 1.41 & 0.04 & & 0.94 & 0.07 \\
Internet journalism & 1 & 3 & 2.74 & 0.52 & -1.84 & 0.04 & & 2.53 & 0.07 \\
Social media & 1 & 3 & 2.73 & 0.54 & -1.87 & 0.04 & & 2.54 & 0.07 \\
\hline
\end{tabular}


Table 2. Intercorrelation among the study variables

\begin{tabular}{lcccccccccc}
\hline Variable & 1 & 2 & 3 & 4 & 5 & 6 & 7 & 8 & 9 & 10 \\
\hline 1. Age & 1 & & & & & & & & \\
2. Gender & $.36^{* *}$ & 1 & & & & & & & \\
3. Education level & $.19^{* *}$ & .01 & 1 & & & & & & \\
4. Economic level & $.16^{* *}$ & $.06^{* *}$ & $.15^{* *}$ & 1 & & & & & \\
5. TV & $.14^{* *}$ & -.01 & $-.06^{* *}$ & .01 & 1 & & & & \\
6. Friends and family & $-.21^{* *}$ & $-.22^{* *}$ & -.00 & .00 & $.04^{* *}$ & 1 & & & \\
7. Informative meetings & $.09^{* *}$ & .03 & $.05^{* *}$ & $.05^{* *}$ & $.11^{* *}$ & $.08^{* *}$ & 1 & & & \\
8. Newspaper & $.21^{* *}$ & $.07^{* *}$ & $.09^{* *}$ & $.06^{* *}$ & $.13^{* *}$ & .01 & $.23^{* *}$ & 1 & & \\
9. Internet journalism & -.00 & .00 & $.06^{* *}$ & $.03^{*}$ & $.09^{* *}$ & $.09^{* *}$ & $.07^{* *}$ & $.15^{* *}$ & 1 & \\
10. Social media & $-.18^{* * *}$ & $-.12^{* *}$ & .01 & -.02 & .01 & $.21^{* *}$ & -.01 & $-.06^{* *}$ & $.21^{* *}$ & 1 \\
\hline
\end{tabular}

**. $p<0.01 ; * . p<0.05$ 
Table 3. T-test independent sample results of the comparison between gender with source of information

\begin{tabular}{llcccccc}
\hline Information source & Gender & $\mathrm{N}$ & Mean & $\mathrm{SD}$ & $\mathrm{t}$ & $\mathrm{df}$ & $p$ \\
\hline \multirow{2}{*}{ FV } & Female & 3236 & 2.21 & 0.71 & \multirow{2}{*}{0.56} & 4622 & 0.58 \\
& Male & 1388 & 2.20 & 0.72 & & & \\
& Female & 3236 & 2.46 & 0.61 & & & \\
\multirow{3}{*}{ Informative meetings } & Memale & 3236 & 1.43 & 0.66 & & & \\
& Male & 1388 & 1.47 & 0.64 & & & \\
\multirow{2}{*}{ Newspaper } & Female & 3236 & 1.33 & 0.57 & & & \\
\multirow{2}{*}{ Internet journalism } & Male & 1388 & 1.42 & 0.62 & -4.72 & 2444.91 & 0.00 \\
& Female & 3236 & 2.74 & 0.52 & & & \\
\multirow{2}{*}{ Social media } & Male & 1388 & 2.74 & 0.52 & -0.27 & 4622 & 0.78 \\
& Female & 3236 & 2.77 & 0.51 & & & \\
& Male & 1388 & 2.63 & 0.60 & 7.85 & 2272.63 & 0.00 \\
\hline
\end{tabular}


Table 4. Means and standard deviations of source of information by education level

\begin{tabular}{|c|c|c|c|c|}
\hline Information source & Education level & $\mathrm{N}$ & Mean & $\mathrm{SD}$ \\
\hline \multirow{3}{*}{$T V$} & High school graduate or below & 500 & 2.29 & 0.72 \\
\hline & University graduate & 2932 & 2.22 & 0.70 \\
\hline & Postgraduate graduate & 1192 & 2.15 & 0.74 \\
\hline \multirow{3}{*}{ Friends family } & High school graduate or below & 500 & 2.31 & 0.65 \\
\hline & University graduate & 2932 & 2.39 & 0.62 \\
\hline & Postgraduate graduate & 1192 & 2.34 & 0.64 \\
\hline \multirow{3}{*}{ Informative meetings } & High school graduate or below & 500 & 1.40 & 0.67 \\
\hline & University graduate & 2932 & 1.43 & 0.64 \\
\hline & Postgraduate graduate & 1192 & 1.51 & 0.68 \\
\hline \multirow{3}{*}{ Newspaper } & High school graduate or below & 500 & 1.31 & 0.54 \\
\hline & University graduate & 2932 & 1.33 & 0.57 \\
\hline & Postgraduate graduate & 1192 & 1.46 & 0.64 \\
\hline \multirow{3}{*}{ Internet journalism } & High school graduate or below & 500 & 2.62 & 0.63 \\
\hline & University graduate & 2932 & 2.75 & 0.50 \\
\hline & Postgraduate graduate & 1192 & 2.75 & 0.51 \\
\hline \multirow{3}{*}{ Social media } & High school graduate or below & 500 & 2.62 & 0.62 \\
\hline & University graduate & 2932 & 2.76 & 0.52 \\
\hline & Postgraduate graduate & 1192 & 2.70 & 0.56 \\
\hline
\end{tabular}


Table 5. Means and standard deviations of source of information by economic level

\begin{tabular}{|c|c|c|c|c|}
\hline Information source & Economic level & $\mathrm{N}$ & Mean & $\mathrm{SD}$ \\
\hline \multirow{3}{*}{$T V$} & Low & 578 & 2.13 & 0.74 \\
\hline & Medium & 3557 & 2.22 & 0.71 \\
\hline & High & 489 & 2.16 & 0.74 \\
\hline \multirow{3}{*}{ Friends and family } & Low & 578 & 2.34 & 0.63 \\
\hline & Medium & 3557 & 2.37 & 0.63 \\
\hline & High & 489 & 2.34 & 0.64 \\
\hline \multirow{3}{*}{ Informative meetings } & Low & 578 & 1.37 & 0.66 \\
\hline & Medium & 3557 & 1.45 & 0.65 \\
\hline & High & 489 & 1.50 & 0.67 \\
\hline \multirow{3}{*}{ Newspaper } & Low & 578 & 1.30 & 0.55 \\
\hline & Medium & 3557 & 1.36 & 0.59 \\
\hline & High & 489 & 1.45 & 0.65 \\
\hline \multirow{3}{*}{ Internet journalism } & Low & 578 & 2.71 & 0.55 \\
\hline & Medium & 3557 & 2.74 & 0.51 \\
\hline & High & 489 & 2.78 & 0.51 \\
\hline \multirow{3}{*}{ Social media } & Low & 578 & 2.74 & 0.55 \\
\hline & Medium & 3557 & 2.73 & 0.54 \\
\hline & High & 489 & 2.70 & 0.54 \\
\hline
\end{tabular}

